however, of interest, and it is convenient to have it recorded in the form of a book.

\section{Human and Experimental Breast Cancer}

Grorgiana M. Bonser, M.D., F.R.C.P. John A. DossetT, M.D., and John W. Jull, Ph.D. Pp. $\mathrm{x}+$ 485 , illustrated. London: Pitman Medical. i96i. £6 6 s.

This is a comprehensive study of the biological aspects of human and experimental mammary cancer. In the two introductory chapters the bare outlines of endocrinology and of factors concerned in the induction and growth of cancer are given. The next four chapters deal with the basic structure of the mammary gland in man and in laboratory animals, and with the physiological control of its growth and differentiation. Three chapters are devoted to mammary cancer in experimental animals. Human fibroadenoma, duct ectasia, cystic disease, and epithelial proliferations are covered in four excellent chapters, and human mammary cancer is dealt with in the remaining five chapters. Three cover problems of therapy, but surgical anctomy and pathology are not considered.

Throughout the work, emphasis is laid on physiological factors, and in the chapters dealing with animals the relevance of the findings are carefully discussed in relation to the corresponding conditions in man. There is a uniformity and balance of presentation not often found in a work of multiple authorship. The arguments on the many controversial topics are given simply and with clarity and the authors are always careful to state their own conclusions and their reasons for holding them. The text is a pleasure to read, and is supported by clear tables, diagrams, and by a large number of well-chosen photomicrographs of a very high standard.

This is a very important book and is likely to become a classic. It will be an indispensable source of reference for many years to come, and is highly recommended to surgeons, pathologists, radiotherapists and those engaged in experimental cancer research.

\section{The Principles of Pathology, including Bacteriology}

R. A. WILlis, D.SC., M.D., F.R.C.P., F.R.C.S. Second edition. Pp. xiv $+719,291$ illustrations. London: Butterworths. 1961. 75 s.

This book is designed primarily as a standard text for systematic reading by medical students; but its clear, direct style and unostentatiously paternal tone will commend it also to the postgraduate who wishes to revise and modernize his knowledge of pathology. Professor Willis has deliberately broken with the tradition, which dates from Rokitansky, that ætiology is dealt with in one section and systemic pathology in another; he has done so by adopting an ætiological framework and fitting in the systematic descriptions where they are relevant. This makes for readability by cutting down the need for cross-reference (and it is an excellent point that when cross-reference does become necessary, it is usually supplied in the text, by page number), but it is less felicitous if one attempts to establish, say, possible causes of a disorder of the spleen.

Despite succinct presentation, an absence of whimsy, and a firm hand with controversial subjects - the whole of nephritis, for example, is dealt with in 12 pagesthis is not a small book. Perhaps the most debatable inclusion is the bacteriological section: a popular feature, no doubt, if it could save the hard-pressed student from buying a separate textbook, but this is unlikely. The real intention, of integrating two sub- jects that, like parallel lines, run together but never quite meet, is a better justification. It is this kind of integration of pathology with the other subjects on which it bears that stamps this book as a professional production, well fitted to its purpose. As one would expect from such a well-tried combination of author and publisher, typography, illustrations and proofreading are immaculate.

\section{The Facts of Mental Health and Illness}

K. R. Stallworthy, M.B., CH.B., Dip.Psych.Med. Third edition. Pp. 227. Christchurch, New Zealand: N. M. Peryer. 196r. 24s.

The third edition of this book can be recommended to those laymen who want a succinct and readable account of present-day psychiatry, written in straightforward English. The book is based on lectures in mental hygiene given by the author to adult education classes in New Zealand. It includes an introduction to normal and abnormal psychology and the physiology of emotions, and has chapters on sex, marriage, minor neurotic disorders, major breakdowns, mental hospitals, epilepsy, and a brief but realistic account of the psychiatrist's attitude to punishment and the persistent offender. Recent developments such as day hospitals, community care, tranquillizers and anti-depressive drugs are all mentioned but a reference to the role of the reticular activating system in the regulation of consciousness is lacking and might well replace the rather lengthy section on endocrine abnormalities. The book is concise and has a short index but it is poorly bound and, considering its aim to be a popular text, it should be cheaper.

Neuromuscular Disorders. Research Investigations of the Association for Research in Nervous and Mental Diseases, Vol. $3^{8}$.

Editors: Raymond D. Adams, LeE M. Eaton and G. Milton Shy. Pp. xx +813 , illustrated. London: Baillière, Tindall and Cox. I960 I60s.

This publication is based on the 1958 symposium of the Association for Research in Nervous and Mental Diseases and represents a valuable addition to a series that has produced some volumes of outstanding importance in the past. Since the volume runs into some 813 pages, it is possible to do little else in this review other than to list the contents.

The material is divided into five sections. The first is devoted to the basic structure and function of the motor unit, beginning with a discussion of the general anatomical and physiological organization of the motor unit by Buchthal. Chapters on the ultrastructure of the neuromuscular junction and the muscle fibre are provided by Hodge and Lehrer, and on the biochemistry of muscular contraction by Gergely. The section ends with a review of nerve excitation, conduction and neuromuscular transmission by del Castillo.

The second part consists of chapters on the experimental pathology of muscle by Denny-Brown and on experimental myopathies by Banker. An interesting inclusion is a chapter on diseases of skeletal muscle in animals.

The third part begins with a succinct account of clinical electromyography and the study of nerve conduction and muscle stimulation by Lambert. This is followed by a most able chapter on metabolic and endocrinological aspects of muscle disorders by Shy and another on muscle histopathology by Adams.

The fourth part is devoted to a consideration of clinical aspects of muscle disorder and includes chapters 
on the genetics of neuromuscular disease, and on myasthenia and myotonia. There is an important chapter on chronic progressive disorders of the lower motor neuron by Gamstorp and the late Professor Gunnar Wohlfart.

The final part consists of a selection of experimental techniques likely to yield results of interest in the study of neuromuscular disorders in the future, including tissue culture, microelectrode studies of membrane potential in man, and the measurement of refractory period, enzyme studies and fluorescent antibody techniques.

In the field of neuromuscular disorders, substantial additions to our knowledge have been made in recent years, partly by clinical and histopathological analysis and partly by the introduction of new laboratory techniques. This volume, although not giving a complete coverage of the field, has gathered together a considerable number of valuable contributions by many of those who have been responsible for these advances.

\section{Advances in Biology of Skin, Vol. 2, Blood Vessels and Circulation}

Editors: W. Montagna, and R. A. Ellis, Pp. I56, illustrated. Oxford, London, New York, Paris: Pergamon Press. 1961. £.3 35 .

This book presents the proceedings of the Brown University Symposium on the Biology of the Skin, held in 1960. There are thirteen contributors to its nine chapters. It opens with two chapters on vascular patterns, the first by Winkelmann and his colleagues on India ink injection and alkaline-phosphatase reaction studies, the second by Ellis based on thick frozen section alkaline phosphatase studies. Other chapters deal with capillary microscopy, X-ray projection microscopy and electron microscopy. There is a short chapter by Weddell on innervation of cutaneous blood vessels and a longer one by Hertzman on the effects of heat on cutaneous blood flow. In a chapter on special features of the circulation of the skin, Burton concludes that the subservience of the requirements of the skin cells, with respect to control of their circulation, to the service of the whole organism may render them peculiarly susceptible to ischæmia in diseased states. Urbach in his chapter on the blood supply of tumours speculates on carcinogenesis and offers a 'unified' theory based on Pasteur's 'Life without Air is the Key to the problem of Cancer'.

This well illustrated book is, perhaps, of greater interest to the laboratory worker and experimentalist than to the practising physician, but it indicates the likely lines of further research in this important field. It should certainly be in all medical libraries.

\section{Medicine in Tropical Africa}

Michael Gelfand, C.B.E., M.D., F.R.C.P., D.P.H., D.M.R. Pp. 243, illustrated. Edinburgh and London: E. \& S. Livingstone. 1961. 30s.

Dr. Gelfand has not only made many valuable contributions to periodicals largely concerned with tropical medicine; he is also a prolific writer on medical and para-medical subjects that impinge upon medical practice in Central Africa.

In the present volume, he has taken a step back from the bedside, and has stood and stared at the clinical and epidemiological problems confronting the thoughtful practitioner in the tropics, bringing a mature and res flective mind to bear upon the wealth of clinical exo perience at his disposal and the fruit of wide reading His main purpose is to view the 'sick African' in hik various settings, and to assess the interplay of hereditary and nutritional factors, of parasitic infection-ofters. multiple - and of a multiplicity of static and changing environments.

This is not a book for the beginner-it presumes certain amount of factual knowledge of tropical diseases but it is intended for the practitioner in town or bush ir tropical Africa who realizes his need for orientations Too frequently, specialists have insisted that the " wood $\mathbb{D}$ consists exclusively of their own pet ' trees ', to the con fusion of the doctor in daily touch with sick individuals, and to the detriment-be it admitted - of the patients who may indeed harbour this or that parasite, but whose total clinical condition may be due to either a multiplicity of parasitological infections or to uno suspected and extraneous conditions.

Not all will agree with . every statement of Dio Gelfand's, and some will suggest that here and there the emphasis is somewhat misplaced or one-sided. But thi is an individual book, and no reader will fail to profit from the stimulating and provocative presentation ot many practical problems.

The photographs are very well reproduced, but the text is unfortunately marred by many misprints and mis-spellings.

Lectures on the Methodology of Clinical Research

Max. Hamilton, M.D., D.P.M. Pp. viii $+\mathrm{I} 39$ 疋 illustrated. Edinburgh and London: E. \& Livingstone. 1961. $21 s$.

The set of lectures on which this book is based sprof from the author's opinion that 'clinical practice negis much more science than it has had heretofore. It is க⿳亠丷厂巾 sufficient for the clinician to rely on his empirixa? " experience" and ability to understand the patient as a human being, leaving the "science" to specialists and technicians'. Since I 953 the lectures have been giverof annually to an audience which included 'physicians surgeons, obstetricians, anæsthetists, clinical pathologists and psychiatrists'. The author has been tempted to puㅡㅡㅁ them into book form because, although there are manj excellent books on statistical methods and the design of experiments, there are few that deal directly with the problems of clinical medicine.

The result is a short book with a strong individuap flavour and one which can be heartily recommended t\% clinicians who wish to get an idea of the principles tha? underly experimental design and the various tests of. statistical significance. As the author is himself a clinicab research worker, he is able to discuss various medicas situations in a way which is understandable to other doctors, and it is this which gives the book its speciaf value.

Although the author writes plainly, it must not be supposed that this is a book which any doctor will find easy to read, because our standard of clinical education is so lacking in scientific method that most doctors find difficulty in grasping the most elementary statistica 5 concepts. Nevertheless, if they persist with this bookN they are bound to gain some understanding of the powerful and elegant methods that are available for solving clinical problems. The book does not take the place of standard textbooks of statistical methods, but if does serve as an admirable introduction to them. 